\title{
REVIEWS.
}

\section{FUNDAMENTALS OF} ANATOMY.

By Carl C. Francis, A.B., M.D. Henry Kimpton. 1937. Price 12/6.

This volume is accurately described as the "Fundamentals of Anatomy" and as such can be most warmly recommended to the junior medical student, the nurse and even to the intelligent layman so direct and simple is the language. The purpose of a particular tissue or organ is always discussed as a preliminary to a description of its structure and in this way an interest is aroused in the subject which should go a long distance in rebutting the too frequent statement that anatomy is a dry-as-dust study and simply a feat of the memory.

The book is profusely illustrated by pictures in colour as well as in black and white, there is a most comprehensive index and, in addition, a good glossary which should be of great assistance to the young or inexperienced reader.

\section{POST-GRADUATE SURGERY.}

By Rodney MaIngot, Vol. III. Medical Publications. 1937. Price 70/- per volume.

The third volume of this text book is devoted to hernia, eye, ear, nose and throat, pharynx, larynx, œsophagus, diaphragm, endoscopic methods, jaws, teeth, tongue, plastic surgery, obstetric surgery, cardiovascular and lymphatic systems, venereal diseases, deep X-ray therapy, physical medicine, and orthopædics. It thus covers a very comprehensive field. The section on hernia is well written, and sets out recent teaching to full advantage. The author rightly places the Bassini operation in the museum and describes a method of operating on inguinal herniæ with silk ligaturesa method we have not used heretofore. Every surgeon, however, has his own particular operation to which he gives preference.

One hundred and thirty pages are given to plastic surgery, which receives very full consideration. Such procedures as taking the wrinkles out of the forehead, removing skin from baggy eyelids, beautifying the breast by raising the nipple, and partial mamectomy together with face lifting appear for the first time in a British text book of surgery and are given much space. The author has, however, omitted to describe the operation for removing fat from the buttock and from the anterior abdominal wall. Little guidance is to be found as to the measures and precautions to be taken to avoid keloid formation, the one bugbear of the plastic surgeon. The operation advocated for the closure of the hard and soft palate is a recently-described and untried modification of Veau's excellent technique.

In the chapters on the lymphatic system, much undue prominence is devoted to the lymphatic permeation theory of the spread of carcinoma. The concensus of opinion among pathologists in London to-day is not to accept this theory in toto. Lymphatic spread does occur but it is believed that the more usual mode of spread of carcinoma to distant parts is by embolism-either carried by the blood stream or by the lymphatics.

The book is full of really excellent material, and the points raised above are minor ones. The work on the tongue is a section which stands out on account of its merit as does that dealing with the operation on the eyes.

We can heartily recommend this book to all surgeons and especially to those Empire builders who are going out into the world away from contact with colleagues, and who will necessarily find themselves alone on the surgical raft.

\section{THE BRITISH ENCYCLOP EDIA OF IMEDICAL PRACTICE.}

Edited by SiR Humphry Rolleston, Bt., G.C.V.O., K.C.B. Vol. 5 (Endoscopy of Respiratory Tract to Goitre), Vol. 6 (Gonorrhea to Hydrotherapy). Butterworth Medical Publications. 1937. Price $35 /-$ per volume.

These two volumes maintain the high standard set by their predecessors and they convince one more than ever that the complete encyclopædia will be a most valuable addition to the library of every medical man.

The comprehensiveness of the work is very well revealed in volume 5 , treating as it does of such a wide variety of subjects in so many fields of medicine, e.g. diseases of 